\title{
DAMPAK PEMANASAN GLOBAL TERHADAP RISIKO TERJADINYA MALARIA
}

\author{
Artha Budi Susila Duarsa*
}

\section{Pendahuluan}

Malaria adalah salah satu penyebab utama penyakit dan kematian di seluruh dunia. Sekitar 2.4 milyar manusia berhadapan dengan risiko penyakit ini. Saat ini malaria endemik di 92 negara, dan terdapat pada kantungkantung penularan malaria di berbagai negara (WHO dalam Martens, 2002). Terdapat 300-500 juta kasus klinis malaria, dimana lebih dari $90 \%$ terjadi di Sub Sahara Afrika. Di seluruh dunia, malaria menyebabkan 2 juta kematian setiap tahun, dan kematian ini terbanyak terjadi pada anak-anak dibawah lima tahun. Dari semua penyakit menular, malaria selalu menjadi penyebab terbesar penderitaan dan kematian di dunia ${ }^{1}$.

Risiko terjadinya malaria ditentukan oleh banyak faktor, terutama jenis spesies nyamuk Anopheles, perilaku manusia, dan adanya parasit malaria. Suatu perubahan dari faktor yang manapun, akan mempengaruhi risiko terjadinya malaria. Saat ini perhatian dunia kepada risiko terjadinya malaria mengarah kepada dampak potensial perubahan global. Lingkungan geografis malaria telah berubah sebagai respon terhadap perubahan iklim, pola penggunaan lahan, biodiversitas (keneka ragaman hayati), dan struktur sosiodemografi (termasuk urbanisasi).

\section{Pemanasan Global}

Gas rumah kaca yang menumpuk di atmosfer berlaku seperti tirai yang memerangkap pancaran radiasi panas bumi. Seperti kaca, ia mudah ditembus oleh sinar tampak, tapi mengurung gelombang panjang. Dalam konteks rumah kaca secara harfiah, radiasi gelombang panjang yang terpancar itu tak bisa keluar, karena tak mampu menembus atap dan dinding kaca. Ia berputar-putar di dalam dan sebagian terserap molekul oleh gas-gas rumah kaca. (CO2, N2O dll) dan membuat suhu udara lebih panas. Dalam kontek pemanasan global (global warming), kehadiran gas-gas pencemar di atmosfer itu berperan seperti atap atau dinding kaca. Mereka menghalangi pancaran radiasi gelombang panjang oleh permukaan bumi, laut dan benda-benda di atasnya, baik itu mahluk hidup maupun benda mati ${ }^{14}$.
Diantara gas-gas rumah kaca yang kini diketahui lebih dari 30 jenis. Gas rumah kaca yang penting adalah karbondioksida (CO2), methane $(\mathrm{CH} 4)$, nitrous okside (N2O), Chloroflourcarbon (CFC) yang terdiri dari Haloflourocarbon (HFC) dan Perflourocarbon (PFC) serta Sulfur Hexafluoride (SF6). Sumbangan terjadinya pemanasan global yang terbesar adalah $\mathrm{CO} 2$ sebesar $61 \%$, $\mathrm{CH} 4$ sebesar $15 \%$, CFC sebesar $12 \%$, N2O sebesar $4 \%$ dan sumber lain sebesar $8 \%$.

Di awal-awal revolusi industri sekitar tahun 1800 , konsentrasi CO2 di atmosfer rata-rata baru pada $280 \mathrm{ppm}$ (parts per million). Artinya, ada 280 molekul CO2 dalam setiap satu juta molekul udara. Namun, juli 2007 lalu IPCC (Intergovernmental Panel on Climate Change) melaporkan konsentrasi karbon dioksida telah mencapai 383 ppm (Trihusodo, P, Gatra 22 - 28 November 2007). Hingga kini $\mathrm{CO} 2$ masih terus meningkat rata-rata mencapai $0,4 \%$ per tahun, yang disebabkan oleh karena pembakaran bahan bakar fosil dan pembotakan hutan.

Kalau tidak ada upaya yang serius untuk menekan emisi gas-gas rumah kaca, tahun 2050 nanti konsentrasinya akan melampaui $560 \mathrm{ppm}$. Suhu bumi akan naik rata-rata 2 - $3^{\circ} \mathrm{C}$ dan dipastikan akan terjadi perubahan iklim dunia. Atmosfer bumi dengan bagian utamanya troposfer yang tebalnya tak sampai 13 kilometer, akan mengalami guncangan luar biasa. Peran atmosfer, yang selama lebih dari dua juta tahun menjaga harmoni kehidupan di muka bumi akan hancur lebih cepat ${ }^{14}$.

\section{Perubahan Iklim}

Perubahan suhu global akan berdampak pada perubahan iklim dan akan menambah daftar risiko kesehatan lingkungan bagi manusia. Paparan terhadap perubahanperubahan lingkungan di atas dapat menimbulkan berbagai problem kesehatan, seperti penyakit-penyakit terkait suhu dan cuaca ekstrim, penyakit yang menular lewat makanan, air dan vektor serta penyakit akibat pencemaran udara ${ }^{12}$. Perubahan iklim akan mempengaruhi suhu lingkungan dan juga kesehatan, seperti diperlihatkan pada gambar 1 . 


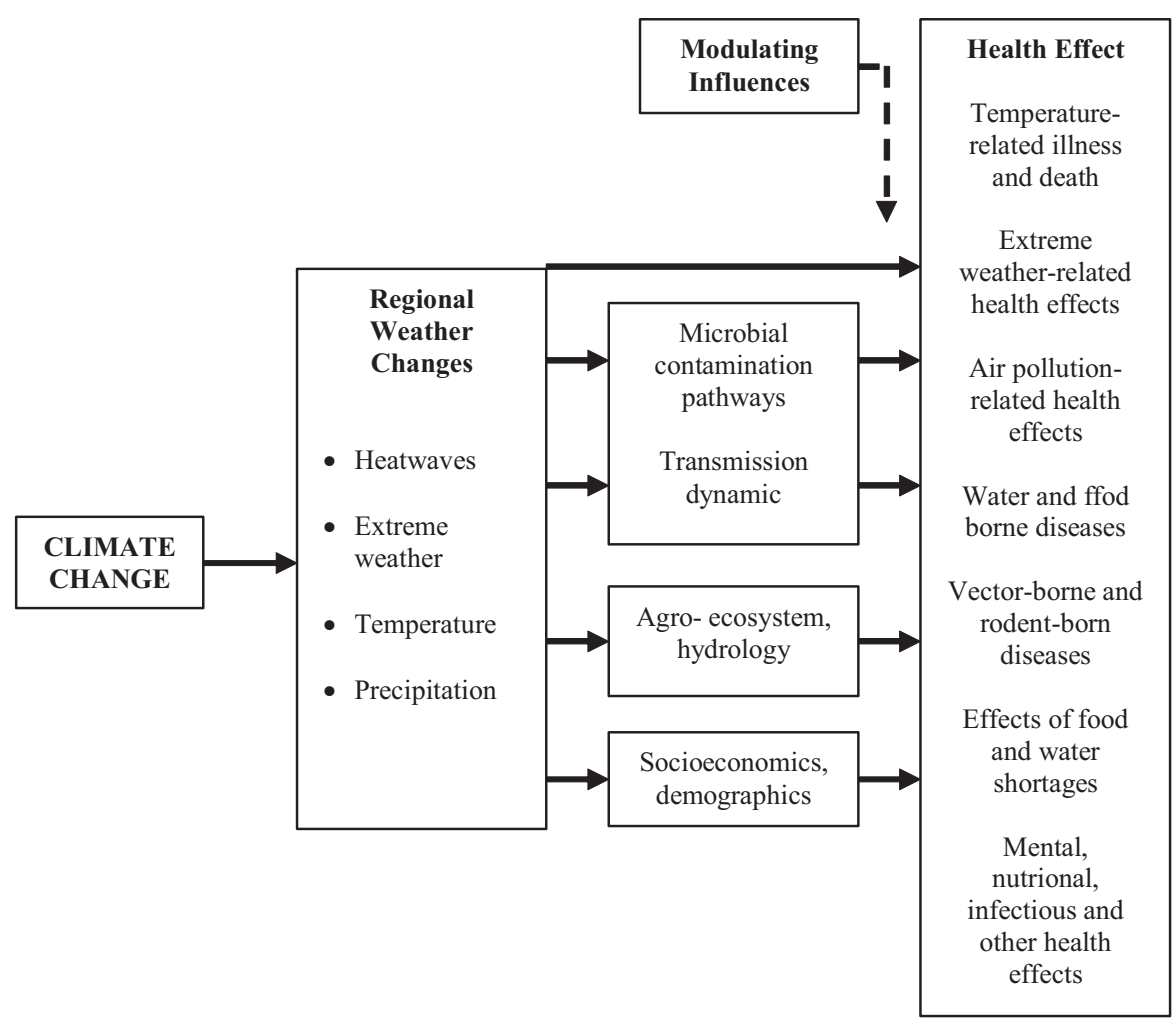

Gambar 1.

Pengaruh Perubahan Iklim, Suhu, Lingkungan dan Kesehatan

(IPPC dalam Romadhiyani, 2007)

Malaria sangat peka terhadap perubahan iklim. Diperkirakan bahwa rata-rata suhu global akan meningkat $1,0^{\circ}-3,5^{\circ} \mathrm{C}$ pada tahun 2100 , yang akan meningkatkan jumlah vector-borne disease dan terjadinya transmisi penyakit. Perubahan iklim akan memiliki dampak jangka panjang dan jangka pendek terhadap transmisi malaria. Dalam jangka pendek dapat dilihat pada suhu dan curah hujan $^{5}$.

Udara panas dan lembab paling cocok untuk nyamuk Anopheles. Dulu, nyamuk Anopheles lebih sering muncul di musim pancaroba, transisi antara musim hujan dan kemarau. Namun kini rentang waktu serangan nyamuk ini hampir sepanjang tahun. Udara panas lembab berlangsung sepanjang tahun, ditambah dengan sanitasi buruk yang selalu menyediakan genangan air untuk bertelur, sehingga nyamuk Anopheles dapat menyerang sewaktu-waktu secara ganas. WHO menjelaskan bahwa kontribusi perubahan iklim terhadap kasus malaria mencapai $6 \%$ di sejumlah negara ${ }^{8}$.

Suhu udara sangat mempengaruhi panjang pendeknya siklus sporogoni atau masa inkubasi intrinsik. Makin tinggi suhu (sampai batas tertentu) makin pendek masa inkubasi intrinsik, begitu juga sebaliknya. Siklus hidup nyamuk makin pendek, populasinya gampang meledak dan penularan semakin cepat. Sejak tahun 1988, terdapat sejumlah laporan mengenai epidemi malaria di Afrika Selatan dan Timur. Selama periode ini terjadi peningkatan suhu sekitar $2^{\circ} \mathrm{C}$ pada rata-rata suhu maksimum bulanan antara daerah pada $2^{\circ} \mathrm{LU}-2^{\circ} \mathrm{LS}$ dan $30^{\circ} \mathrm{BB}-40^{\circ} \mathrm{BT}$. Selanjutnya epidemi malaria yang berhubungan dengan iklim juga dilaporkan di Rwanda, Tanjania dan Kenya Barat.

Pada umumnya hujan akan memudahkan perkembangan nyamuk dan terjadinya epidemi malaria. Terdapat hubungan langsung antara hujan dan perkembangan larva nyamuk menjadi dewasa. Besar kecilnya pengaruh tergantung pada jenis hujan, derasnya hujan, jumlah hari hujan, jenis vektor dan jenis tempat perindukan (breeding places). Hujan yang diselingi panas akan memperbesar kemungkinan berkembang biaknya Anopheles ${ }^{2}$.

Menurut WHO dalam Susanna (2005), di banyak tempat kejadian malaria berhubungan dengan musim hujan, namun korelasinya tidak selalu jelas dan terkadang anomali. Hujan akan menguntungkan perkembang biakan nyamuk jika tidak terlalu deras, karena bila terlalu deras akan membilas larva nyamuk. Namun di daerah lain, musim kemarau justru menyebakan epidemi malaria, juga sebaliknya di daerah lain dapat melenyapkan nyamuk Anopheles. Variasinya amat beragam, sehingga pengaruh hujan hanya dapat diperkirakan hubungannya dalam pola lokal perkembang biakan vektor. 
Hujan juga dapat meningkatkan kelembaban relatif, sehingga memperpanjang usia nyamuk dewasa. Curah hujan minimum yang dibutuhkan oleh nyamuk untuk berkembang adalah $1,5 \mathrm{~mm}$ per hari (Martens, 2002). Curah hujan $150 \mathrm{~mm}$ per bulan mengakibatkan perkembangan yang pesat populasi An. gambiae, vektor malaria di Kenya (Malakooti, dalam Susanna, 2005). Suwasono dalam Susanna (2005) dalam studinya di Kabupaten Kulonprogo, menunjukkan bahwa kasus malaria meningkat setelah terjadi peningkatan curah hujan yang relatif tinggi.

Untuk menilai dampak kesehatan yang berhubungan dengan perubahan iklim, pemodelan framework MIASMA ecoepidemiological (Modeling Framework for Health Impact Assessment of Man-Induced Atmospheric Changes) telah dikembangkan di Universitas Maastricht. Model diarahkan oleh skenario dari gambaran populasi dan perubahan atmosfer, berdasarkan data dasar mengenai insidens penyakit, keadaan iklim, dan ketebalan lapisan ozon (Martens, 2002). Integrated Model terjadinya malaria tersebut merupakan pendekatan pemodelan yang terintegrasi yang berupaya memberikan gambaran yang komprehensif interaksi antara perubahan atmosfer dan masyarakat.

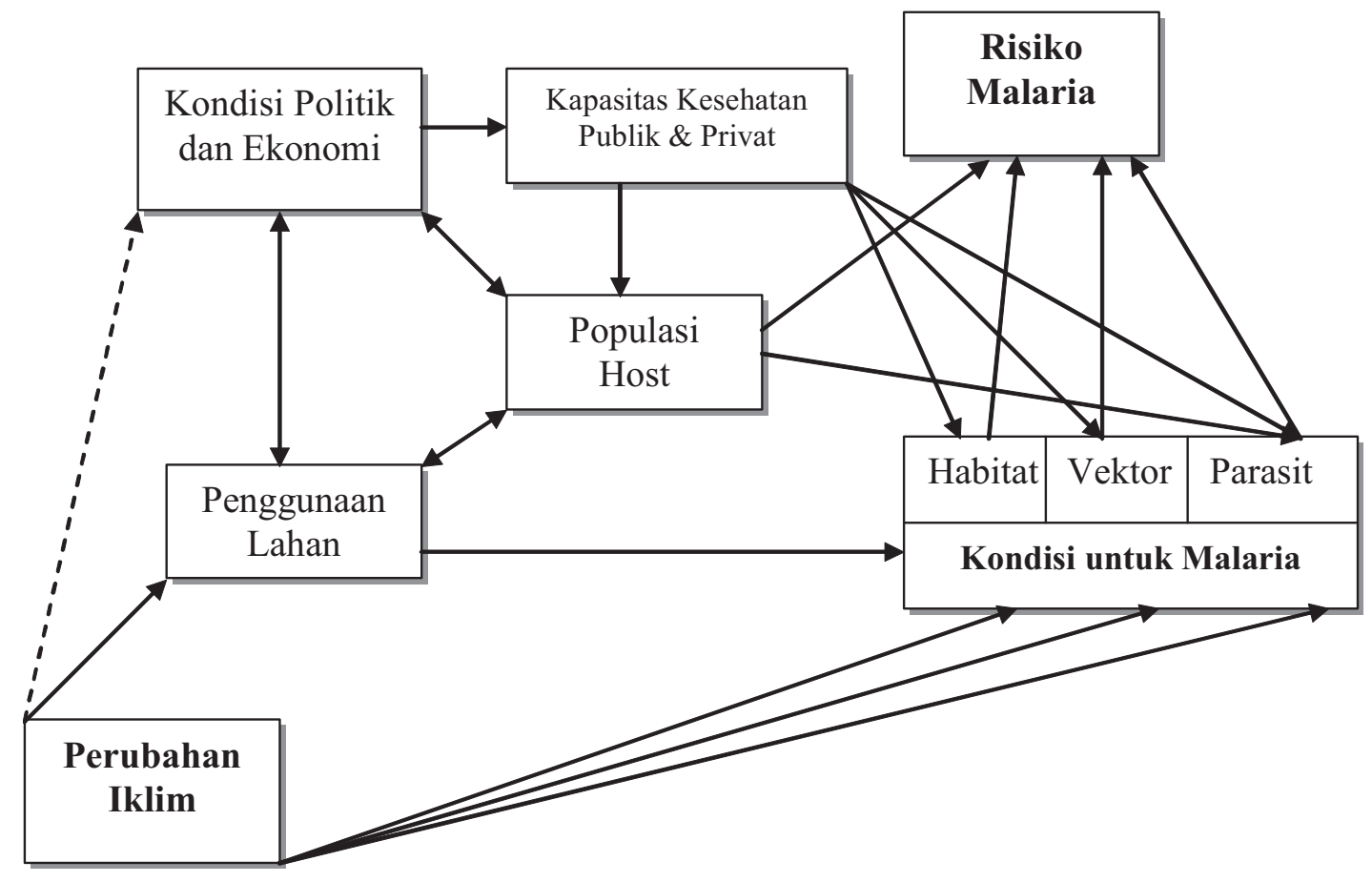

Gambar 2.

Model Hubungan Faktor-Faktor Yang Mempengaruhi Kejadian Malaria (Fischhoff dkk. 2002).

Fischhoff dkk. dalam Casman (2002), menjelaskan model tersebut dimana, kondisi-kondisi untuk malaria terdiri dari habitat, vektor dan parasit. Iklim mempengaruhi variable upstream (tingkat yang lebih tinggi) melalui berbagai jalan, terhadap risiko malaria. Satu jalan yang umum adalah dengan mempengaruhi tingkat perubahan lingkungan lain. Berkurangnya hujan akan mengurangi regenerasi hutan, sedangkan meningkatnya hujan akan sebaliknya. Perubahan waktu hujan akan mempengaruhi kelangsungan hidup pertanian tradisional.

Penggunaan lahan dapat mempengaruhi dan dipengaruhi "Kondisi Politik dan Ekonomi". Kemiskinan sendiri dapat mendorong kegiatan pertanian pada tanah yang kritis, penebangan hutan, dan urbanisasi yang tidak direncanakan.

Penggunaan lahan dan kondisi politik dan ekonomi dapat mempengaruhi keberadaan populasi manusia sebagai host, dengan demikian mempengaruhi risiko malaria. Sebagai contoh, membuka suatu daerah untuk pertanian atau pertambangan akan mendorong migrasi ke daerah populasi yang tidak mendapat pajanan malaria sebelumnya dan mendorong migrasi populasi yang telah terpajan. Semua yang mempengaruhi kondisi politik dan ekonomi dapat mempengaruhi kapasitas kesehatan publik dan privat untuk menanggulangi risiko malaria.

\section{Penggunaan Lahan}

Malaria sebaiknya dipandang sebagai bagian dari suatu ekologi manusia yang lebih besar di mana sistem sosial manusia, aktivitas ekonomi, interaksi dengan lingkungan, dan gaya hidup yang menggambarkan interaksi yang mempengaruhi terjadinya infeksi dan risiko penyakit. Setiap perubahan lingkungan, apakah terjadi akibat peristiwa yang alami atau melalui intervensi manusia, 
akan merubah keseimbangan ekologi dalam konteks penyakit, host, vektor dan jenis parasit dalam perkembangan dan transmisi penyakit.

Secara umum, vektor nyamuk malaria sangat kuat dipengaruhi oleh faktor lingkungan yang mempengaruhi kemampuan hidup dan perkembangan vektor tersebut. Smith dkk. dalam Pattanayak (2003) menemukan bahwa 70$90 \%$ risiko dari malaria adalah faktor lingkungan. Variasi dan besar pengaruh lingkungan kepada vektor malaria sangat besar ${ }^{11}$ tidak hanya melalui elemen yang abiotik seperti hujan dan suhu yang akan mempengaruhi peningkatan jumlah vektor nyamuk dan perkembangan parasit di dalam vektor, tetapi juga faktor biotik melalui penebangan hutan, pertanian, dan konstruksi perumahan. Dampak dari penebangan hutan pada suhu, hujan, dan tumbuh-tumbuhan saling berinteraksi dan berkorelasi dalam pengaruh lingkungan.

Duarsa, A, 2007, dalam penelitiannya mendapatkan bahwa besar peran lingkungan terhadap kejadian infeksi malaria yang terdiri dari tingkat rumah tangga (level 2) dan tingkat desa (level 3) adalah 99,7 \%, dimana $43,8 \%$ adalah besar peran tingkat rumah tangga (level 2) dan 55,9\% adalah besar peran tingkat desa (level 3).

\section{Risiko Malaria Dan Transmisi Potensial Malaria}

Risiko malaria adalah probabilitas untuk terserang malaria yang dapat dihitung baik dalam waktu jangka pendek maupun jangka panjang. Secara umum, risiko individu untuk mengalami infeksi adalah fungsi dari suatu dose-response relationship dari probabilitas pajanan yang didapatkan berkali-kali. Konsep ini didasarkan pada beberapa faktor seperti: kepadatan populasi vektor, probabilitas vektor menjadi infeksius, keberadaan dan prevalensi dari sumber penularan (manusia yang telah terinfeksi) di dalam populasi, probabilitas untuk menerima gigitan yang infektif, tingkat imunitas di populasi dan efektivitas strategi penanggulangan malaria yang digunakan di tempat itu.

Risiko malaria berbeda dengan Transmisi Potensial Malaria (TP), yang fokusnya adalah kecepatan nyamuk dan parasit menjadi matang ${ }^{1}$. Pengukuran risiko malaria perlu menjadi perhatian di masa yang akan datang, oleh karena akibat terjadinya pemanasan global, malaria akan menjadi endemik di daerah yang saat ini bebas malaria.

Transmisi Potensial Malaria (TP) berasal dari basic reproduction rate $\left(R_{o}\right)$, yaitu jumlah infeksi sekunder yang kemungkinan terjadi ketika satu individu terinfeksi masuk ke dalam populasi yang rentan ${ }^{1,6} R_{o}$ didefinisikan sebagai banyaknya kasus baru yang muncul dari kasus saat ini pada populasi host yang rentan selama satu siklus transmisi ${ }^{9}$. Basic reproduction rate $\left(R_{o}\right)$ malaria dipengaruhi oleh jumlah gigitan nyamuk per orang, jumlah gigitan per nyamuk per hari, efisiensi infeksi nyamuk ke manusia, efisiensi infeksi manusia ke nyamuk, probabilitas survival nyamuk, waktu maturasi parasit di dalam nyamuk dan tingkat kesembuhan manusia9 .

$$
R_{0}=\frac{m a^{2} b c p^{n}}{-\ln (p) r}
$$

Dimana:

$m=$ jumlah gigitan nyamuk per orang

$a=$ jumlah gigitan per nyamuk per hari

$b=$ efisiensi infeksi, nyamuk ke manusia

$c=$ efisiensi infeksi, manusia ke nyamuk

$p=$ probabilitas survival nyamuk sehari-hari

$n=$ waktu maturasi parasit di dalam nyamuk

$r=$ tingkat kesembuhan manusia

Versi yang disederhanakan pada persamaan ini, ditetapkan bahwa $b, c, r=1$ (konstan) yang disebut kapasitas vektorial (vectorial capacity/VC). Kapasitas vektorial adalah jumlah maksimum orang yang belum terinfeksi, yang kemungkinan digigit oleh vektor yang telah menggigit satu orang sumber penularan per harinya.

Garrets Jones dan Shidrawi dalam Susanna (2005), menjelaskan bahwa kapasitas vektorial adalah jumlah orang yang secara efektif mampu digigit dan ditulari parasit malaria (sporosoit) oleh seekor nyamuk Anopheles spesies tertentu persatuan waktu (12 jam - satu malam penuh) dari satu sumber penularan (manusia yang telah terinfeksi malaria).

$$
V C=\frac{m a^{2} p^{n}}{-\ln (p)}
$$

Persamaan (3-1) dan (3-2) tidak digunakan dalam MIASMA (Modeling Framework for the Health Impact Assessment of Man-Induced Atmospheric Changes), sebab $m$ memerlukan pengetahuan yang mendetil mengenai kepadatan populasi manusia dan nyamuk. Dengan demikian, TP diperoleh dengan menghitung kepadatan nyamuk $\left(m_{c}\right)$ ketika $R_{o}=1$ (intensitas transmisi stabil).

Penetapan $b, c, r$ menjadi 1 (konstan) membuat persamaan yang digunakan di dalam MIASMA (Modeling Framework for the Health Impact Assessment of Man-Induced Atmospheric Changes) menjadi sederhana, jumlah orang per nyamuk pada saat $\mathrm{VC}=1$ adalah:

$$
T P=\frac{a^{2} p^{n}}{-\ln (p)}
$$

Persamaan yang dihasilkan tersebut berasal dari $R_{o}$, sehingga persamaan untuk TP dapat dituliskan sebagai berikut

$$
\begin{aligned}
& R_{0}=\frac{m a^{2} b c p^{n}}{-\ln (p) r} \text { menjadi: } R o=\frac{m b c \cdot T p}{r} \\
& \text { Sehinga } T P=\frac{\text { Ro.r }}{m b c}
\end{aligned}
$$


Malaria dapat menyebar dengan mudah pada tempat dengan nilai transmisi potensial (TP) yang lebih tinggi sebab memerlukan nyamuk yang lebih sedikit perorang untuk mempunyai efek yang sama. Dengan mengetahui transmisi potensial (TP) kita dapat membandingkan daerah yang cenderung menjadi epidemi

Aktifitas antimalaria tertentu mempunyai hubungan yang jelas untuk parameter pada persamaan $R_{o}$. Imagociding (adulticiding) mempengaruhi $p$ (probabilitas survival nyamuk sehari-hari). Kelambu, kawat kasa, dan repellent mengurangi a (jumlah gigitan per nyamuk per hari). Larvaciding dan modifikasi dari landscape mengurangi $m$ (jumlah nyamuk per orang). Terapi medik mempengaruhi $r$ (tingkat kesembuhan manusia), yang bersama-sama dengan chemoprophylaxis (terapi pencegahan) mempengaruhi $b$ (tingkat infeksi nyamuk kepada manusia).

\section{DAFTAR PUSTAKA}

1. Casman, Elizabeth A. 2002

Malaria Potential and Malaria Risk. Dalam: Casman, Elizabeth A dan Dowlatabadi, H. The Contextual Determinants of Malaria. Resources for the Future. Washington, DC:28-32.

2. Departemen Kesehatan RI. 1999

Modul 1. Epidemiologi Malaria. Jakarta: Direktorat Jenderal PPM \& PLP.

3. Duarsa, A. 2007

Pengaruh Perpaduan Berbagai Determinan Di Tingkat Individu Dan Determinan Di Tingkat Agregat/Ekologi Terhadap Kejadian Infeksi Malaria (Studi Ekologi Dengan Pendekatan Analisis Multilevel Di Kecamatan Endemis Malaria Kabupaten Lampung Selatan). Disertasi. Program Doktor Ilmu Kesehatan Masyarakat. Program Pasca Sarjana Fakultas Kesehatan Masyarakat. Universitas Indonesia.

4. Fischhooff, B, dkk. 2002

Integrated Assessment of Malaria Risk. Dalam: Casman, Elizabeth A dan Dowlatabadi, H. The Contextual Determinants of Malaria. Resources for the Future. Washington, DC:331-348.

5. Githeko, A, dkk. 2000

Climate change and vector-borne diseases: A regional analysis. Bulletin World Health Organization. Geneva. Vol 78: 1136-1144.

6. Halloran, M. 2001

Concept of Transmission and Dynamics. Dalam: Thomas, J dan Weber, D. Epidemiologic Methods for the Study of Infectious Disease. Oxford University Press; New York: 56-111.

7. Hidayat, dkk. 2007

Berselimut Gas Rumah Kaca. Gatra 22 - 28 November 2007

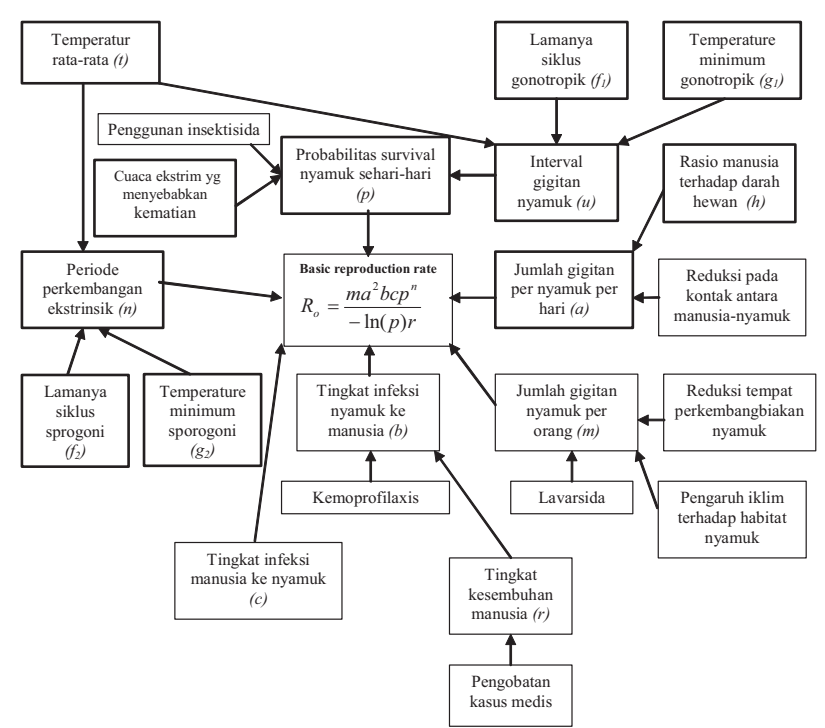

Gambar 3.

Hubungan Pelayanan Kesehatan Masyarakat Dengan Basic Reproduction Rate (Casman, 2002)

8. Kelana, dkk. 2007

Bumi Memanas, Kuman Penyakit Mengganas. Gatra $22-28$ November 2007

9. Martens, P. 2002

Of Malaria and Models, challenges in Modeling Global Climate Change and Malaria Risk. Dalam: Casman, Elizabeth A dan Dowlatabadi, H. The Contextual Determinants of Malaria. Resources for the Future. Washington, DC:14-24.

10. Myrnawati. 2000

Epidemiologi. Jakarta: Bagian Ilmu Kesehatan Masyarakat, Fakultas Kedokteran, Universitas Yarsi. Jakarta.

11. Pattanayak, S, dkk. 2003

Malaria, Deforestation and Poverty: A Call for Interdiciplinary Policy Science. Research Triangle Institute.

12. Romadhiyani, Q. 2007

Ancaman Pencemaran Udara Terhadap Pemanasan Global dan Fungsi Paru. Pidato Pada Upacara Pengukuhan Guru Besar dalam Ilmu Fisiologi Kedokteran pada Fakultas Kedokteran Universitas Yarsi. Jakarta 5 Desember 2007.

13. Susanna, D. 2005

Pola Penularan Malaria Di Ekosistem Persawahan, Perbukitan Dan Pantai (Studi di Kabupaten Jepara, Purworejo Dan Kota Batam). Disertasi. Program Doktor Ilmu Kesehatan Masyarakat. Program Pasca Sarjana Fakultas Kesehatan Masyarakat. Universitas Indonesia.

14. Trihusodo, P. 2007

Rumah Kaca. Gatra 22 - 28 November 2007 